\title{
Nutritional recovery after open and laparoscopic gastrectomies
}

\author{
Shavkat Abdiev $\cdot$ Yasuhiro Kodera $\cdot$ Michitaka Fujiwara $\cdot$ \\ Masahiko Koike • Goro Nakayama • Norifumi Ohashi • \\ Chie Tanaka $\cdot$ Junichi Sakamoto $\cdot$ Akimasa Nakao
}

Received: 3 August 2010/Accepted: 1 December 2010/Published online: 16 February 2011

(C) The International Gastric Cancer Association and The Japanese Gastric Cancer Association 2011

\begin{abstract}
Background The aim of this study was to evaluate longitudinal changes in body composition after laparoscopic and open gastrectomies for gastric cancer.

Methods Body mass, arm muscle mass, leg muscle mass, and fat mass were measured by performing a bioelectrical impedance analysis using a "Bodyscan" body composition analyzer (HXE19-JA; Konami, Tokyo, Japan) in 41 patients who had undergone gastrectomy: 14 patients underwent open distal gastrectomy, 8 patients underwent open total gastrectomy, and 19 patients underwent laparoscopy-assisted distal gastrectomy. All measurements were obtained preoperatively and at 1,3, and 6 months after the operation.

Results Fat mass decreased significantly throughout the 6-month period after distal gastrectomy and until 3 months after the laparoscopic surgery, while similar reductions in the total muscle mass and limb muscle mass were observed only in the first month after operation for all three groups. Patients with the laparoscopic approach had completely regained muscle mass at 6 months postoperatively.

Conclusion Both fat and muscle mass reductions were responsible for the body weight loss during the first postoperative month, whereas loss of fat mass contributed to further weight loss after that period. Enhanced recovery of
\end{abstract}

\footnotetext{
S. Abdiev · Y. Kodera $(\bowtie) \cdot$ M. Fujiwara $\cdot$ M. Koike

G. Nakayama $\cdot$ N. Ohashi $\cdot$ C. Tanaka $\cdot$ A. Nakao

Department of Surgery II, Nagoya University Graduate School

of Medicine, 65 Tsurumai-cho, Showa-ku, Nagoya,

Aichi 466-8550, Japan

e-mail: ykodera@med.nagoya-u.ac.jp

J. Sakamoto

Department of Medical Administration, Nagoya University Graduate School of Medicine, 65 Tsurumai-cho, Showa-ku, Nagoya, Aichi 466-8550, Japan
}

muscle mass at 6 months after laparoscopic surgery suggests the benefit of this surgery, among other factors.

Keywords Body composition - Gastric cancer . Laparoscopic gastrectomy

\section{Introduction}

Body composition is substantially affected by gastrointestinal surgery, and a certain period of time is needed for recovery. Significant changes in nutritional status shortly after distal gastrectomy have been demonstrated by Katsube et al. [1] The laparoscopic approach is considered to be minimally invasive, is considered to result in better short-term outcome [2-5], and is hoped to be oncologically feasible even for advanced gastric cancers [6]. One of the advantages of laparoscopic gastrectomy was reported to be the prevention of overt weight loss, which had generally been explained in terms of decrease in protein mass rather than fat mass [7]. Another study has demonstrated selective loss of fat mass during the first 6 months after open gastrectomy, with a minor decrease of arm circumference [8]. There have been no other longitudinal studies evaluating changes in the composition of the body and extremities after gastrectomy.

The main goal of this study was to observe the trends in muscle and fat masses during the first 6 months after various types of gastrectomies.

\section{Methods}

Patients

Forty-one patients with resectable gastric cancer who underwent gastrectomy and were followed for 6 months 
were analyzed. Twenty-two patients whose cancer was diagnosed to have penetrated as far as the subserosa or deeper were operated by conventional open surgery with D2 lymph node dissection; total gastrectomy (TG) was performed in eight patients and distal gastrectomy (DG) in 14. Roux-en-Y reconstruction was used routinely for this population. Twenty-four patients with the preoperative diagnosis of up to T2 stage gastric cancer underwent laparoscopy-assisted distal gastrectomy (LADG) with D1-D2 lymph node dissection. Billroth I reconstruction was selected for 19 patients. Five patients with preoperative reflux symptoms or extraordinarily small residual stomach underwent Roux-en-Y reconstruction, were considered as atypical cases, and were excluded from this study. Details of the surgical procedures have been reported previously [9-11]. Postoperative adjuvant chemotherapy with S-1 [12] was delivered to 10 patients treated by DG, 3 patients treated by TG, and one patient treated by LADG. Another 3 patients in the TG group received postoperative chemotherapy with S-1/cisplatin (CDDP) and another patient was treated with chemoradiation. Parenteral nutrition was not introduced after surgery in any of the patients.

\section{Measurements of body composition}

Measurements of body composition were performed at the baseline (preoperatively) and at 1, 3, and 6 months after the surgery. Body weight, muscle mass (total mass and upper and lower limb mass), and fat mass (total mass and upper and lower limb mass) were measured using segmental multifrequency bioelectrical impedance analysis performed with the "Bodyscan" HXE19-JA analyzer (Konami, Tokyo, Japan) after obtaining written informed consent from the patients. The height and the waist circumference of each patient were measured before each measurement as parameters that are mandatory for calculating body composition data. Patients with installed pacemakers and those with severe cardiac arrhythmia were not eligible for the study.

\section{Statistical analysis}

General linear models of repeated measures were used for longitudinal analysis. Results are presented in delta values with $95 \%$ confidence intervals (CIs) between two time points. A $p$ value of $<0.05$ was considered to be statistically significant. Statistical analysis was carried out using an SPSS software package (version 15; SPSS, Chicago, IL, USA).

\section{Results}

Patient demographics and tumor stages are presented in Table 1. As has been recommended in the Japanese treatment guidelines for gastric cancer, laparoscopic surgery was indicated for patients with early-stage cancer. The oncological background of patients who underwent LADG and those treated by open surgery was, therefore, completely different, along with the method of reconstruction.

Patients demonstrated a significant body weight loss of $5.55 \mathrm{~kg}(95 \%$ CI $3.81-7.30 \mathrm{~kg})$ during the first month after DG, due to decreases in both the fat $(2.08 \mathrm{~kg}, 95 \% \mathrm{CI}$ $0.70-3.45 \mathrm{~kg})$ and muscle masses $(2.18 \mathrm{~kg}, 95 \% \mathrm{CI}$ 0.77-3.59 kg) (Table 2; Figs. 1, 2, 3). The muscle masses of the upper and lower extremities also decreased by significant margins $[0.37 \mathrm{~kg}(95 \%$ CI $0.07-0.67 \mathrm{~kg})$ and $1.13 \mathrm{~kg}(95 \%$ CI $0.33-1.94 \mathrm{~kg})]$ (Table 2; Figs. 4, 5). After this period, the body weight loss mostly reflected a consistent decrease in the fat mass, while the muscle mass stabilized and even showed a tendency to recover. In the patients with TG, significant losses in the body fat component and the muscle masses of the total body and the upper and lower extremities were observed during the first month [2.40 kg (95\% CI 0.59-4.21 kg), $2.30 \mathrm{~kg}(95 \% \mathrm{CI}$ $0.27-4.33 \mathrm{~kg}), \quad 0.29 \mathrm{~kg} \quad(95 \%$ CI $0.16-0.41 \mathrm{~kg})$, and $1.38 \mathrm{~kg}(95 \%$ CI $0.26-2.51 \mathrm{~kg})$, respectively]. The trend of losing the fat mass went on for 6 months and the trend of losing muscle mass lasted for 3 months, although the differences in fat mass between 3 and 6 months postoperatively and in the muscle between 1 and 3 months were not significant, probably due to the small sample size. In the first month after the LADG, the extent of reduction in the fat mass was $1.87 \mathrm{~kg}$ (95\% CI 1.02-2.73 kg), along with a less prominent loss of muscle mass of $1.11 \mathrm{~kg}(95 \% \mathrm{CI}$ $0.60-1.61 \mathrm{~kg}$ ). During this period, the leg muscle mass decreased by $0.57 \mathrm{~kg}$ (95\% CI $0.13-1.01)$, while the decrease in the arm muscle mass was insignificant. Most notably, the patients started to regain body muscle mass after the first month, and an increase of $0.43 \mathrm{~kg}(95 \% \mathrm{CI}$ $0.03-0.82$ ) was observed by the third month. The total increase from the first to the 6 months postoperatively turned out to be significant, at $0.63 \mathrm{~kg} \quad(95 \%$ CI $0.25-1.27 \mathrm{~kg}$ ). Corresponding recovery was also observed in the lower limb muscle mass $(0.44 \mathrm{~kg}, 95 \%$ CI $0.04-0.83 \mathrm{~kg})$.

At 6 months postoperatively, the total postoperative changes in body composition after the DG and LADG consisted of fat mass reduction by $5.83 \mathrm{~kg}(95 \% \mathrm{CI}$ $3.86-7.79 \mathrm{~kg})$ and $5.40 \mathrm{~kg} \quad(95 \%$ CI $\quad 3.56-7.24 \mathrm{~kg})$, respectively. In addition, total muscle mass after the DG decreased by $1.59 \mathrm{~kg}$ (95\% CI $0.51-2.67 \mathrm{~kg})$, while no significant reduction in the muscle-related parameters at that time point were observed for the LADG group, due to the aforementioned recovery. After the TG, body weight reduction of $9.94 \mathrm{~kg}$ (95\% CI 4.91-14.97 kg) was observed at the 6th postoperative month. 
Table 1 Medical and demographic characteristics of patients
$S D$ standard deviation,

$D G$ distal gastrectomy, $T G$ total gastrectomy, $L A D G$

laparoscopy-assisted distal gastrectomy, $B M I$ body mass index

\begin{tabular}{|c|c|c|c|}
\hline Characteristics & $\mathrm{DG}(N=14)$ & $\mathrm{TG}(N=8)$ & LADG $(N=19)$ \\
\hline Age, years $( \pm \mathrm{SD})$ & $67.2 \pm 10.1$ & $58.13 \pm 18.0$ & $62.0 \pm 10.9$ \\
\hline Male & $13(92.9 \%)$ & $6(80.0 \%)$ & $13(68.5 \%)$ \\
\hline Initial weight $(\mathrm{kg} \pm \mathrm{SD})$ & $63.38 \pm 11.63$ & $60.16 \pm 13.06$ & $58.75 \pm 10.39$ \\
\hline Initial fat mass $(\mathrm{kg} \pm \mathrm{SD})$ & $15.51 \pm 3.39$ & $12.11 \pm 2.33$ & $14.09 \pm 3.37$ \\
\hline Initial total muscle mass $(\mathrm{kg} \pm \mathrm{SD})$ & $20.04 \pm 4.14$ & $19.96 \pm 3.71$ & $18.52 \pm 3.85$ \\
\hline Initial arm muscle mass $(\mathrm{kg} \pm \mathrm{SD})$ & $2.80 \pm 0.69$ & $2.91 \pm 0.55$ & $2.78 \pm 0.86$ \\
\hline Initial leg muscle mass $(\mathrm{kg} \pm \mathrm{SD})$ & $8.83 \pm 2.00$ & $8.67 \pm 1.84$ & $7.93 \pm 2.26$ \\
\hline \multicolumn{4}{|l|}{ BMI } \\
\hline Underweight $<18$ & $1(7.1 \%)$ & $0(0.0 \%)$ & $2(10.5 \%)$ \\
\hline Normal 18-24.9 & $8(57.2 \%)$ & $7(87.5 \%)$ & $15(79.0 \%)$ \\
\hline Overweight $>25$ & $5(35.7 \%)$ & $1(12.5 \%)$ & $2(10.5 \%)$ \\
\hline \multicolumn{4}{|l|}{ Tumor characteristics } \\
\hline \multicolumn{4}{|l|}{ Tumor depth } \\
\hline $\mathrm{T} 1 \mathrm{a} / \mathrm{T} 1 \mathrm{~b}$ & $1 / 1$ & 0 & $17 / 1$ \\
\hline $\mathrm{T} 2$ & 4 & 0 & 1 \\
\hline $\mathrm{T} 3$ & 3 & 3 & 0 \\
\hline $\mathrm{T} 4 \mathrm{a} / \mathrm{T} 4 \mathrm{~b}$ & $4 / 1$ & $4 / 1$ & 0 \\
\hline \multicolumn{4}{|l|}{$\mathrm{N}$ factor } \\
\hline No & 3 & 2 & 19 \\
\hline N1N2 & 11 & 6 & 0 \\
\hline \multicolumn{4}{|l|}{ Stage } \\
\hline IA/IB & $1 / 3$ & 0 & $18 / 1$ \\
\hline IIA/IIB & $0 / 2$ & $0 / 3$ & 0 \\
\hline IIIA/IIIB/IIIC & $0 / 4 / 1$ & $1 / 1 / 0$ & 0 \\
\hline IV & 3 & 3 & \\
\hline \multicolumn{4}{|l|}{ Distant metastasis } \\
\hline M0 & 0 & 6 & 19 \\
\hline M1 & 1 & 2 & 0 \\
\hline Maximal size $(\mathrm{mm} \pm \mathrm{SD})$ & $46.1 \pm 25.2$ & $59.4 \pm 35.8$ & $28.1 \pm 17.2$ \\
\hline Number of removed lymph nodes $( \pm \mathrm{SD})$ & $36.4 \pm 14.2$ & $46.0 \pm 21.7$ & $27.3 \pm 11.2$ \\
\hline Number of positive lymph nodes $( \pm \mathrm{SD})$ & $3.6 \pm 1.1$ & $8.4 \pm 1.6$ & 0 \\
\hline
\end{tabular}

\section{Discussion}

This study is the first report of muscle dynamics after gastrectomy. Our goal was not to make comparisons, between different surgical procedures, of various parameters related to the body composition at each time point, but to observe trends in the nutritional status of the patients after each procedure. Through longitudinal measurements after surgery, interesting data were obtained to speculate on and discuss the process of recovery after major surgery. The total body weight changes observed in our study were due mainly to the change in fat mass, regardless of the type of surgery. In patients with DG and LADG, the loss in fat mass even exceeded the body weight loss at 1-3 months postoperatively, due at least partly to the recovery of muscle mass.

The two prominent mechanisms of fat metabolism, increased consumption and reduced restoring, lead to a profound decrease in fat mass. It is considered that a small gastric remnant (or total resection of the stomach), poor oral food intake, and impaired carbohydrate digestion after gastrectomy lead to insufficient glucose intake, with subsequent depletion of glycogen storage, resulting in loss of body fat mass. In addition, fat malabsorption following gastrectomy is well established to be due to a relative pancreatic insufficiency with low lipase secretion, due to rapid intestinal transit and vagotomic effects [13-15]. The anabolic phase after gastrectomy starts with adequate carbohydrate intake and digestion which initially lead to fat mass stabilization. There was at least a sign of stabilization after the third month for our LADG group, whereas loss of fat mass continued consistently throughout the 6 months of observation for the DG group (Fig. 2). Postoperative chemotherapy given almost exclusively to the DG and TG groups may also have been the cause of reduced food 
Table 2 Body composition parameters (all in $\mathrm{kg}$ ) after open and laparoscopic gastrectomies

\begin{tabular}{llccc}
\hline & $0-1$ Month $[95 \% \mathrm{CI}]$ & $1-3$ Months $[95 \% \mathrm{CI}]$ & $3-6$ Months $[95 \% \mathrm{CI}]$ & $0-6 \mathrm{Months}[95 \% \mathrm{CI}]$ \\
\hline DG & & & & \\
Body weight & $5.55[3.81 ; 7.30]$ & $1.48[0.44 ; 2.51]$ & $1.16[-0.06 ; 2.38]$ & $8.02[6.04 ; 9.99]$ \\
Fat & $2.08[0.70 ; 3.45]$ & $1.91[0.48 ; 3.34]$ & $1.53[0.42 ; 2.65]$ & $5.83[3.86 ; 7.79]$ \\
Muscle & $2.18[0.77 ; 3.59]$ & $-0.23[-0.86 ; 0.40]$ & $-0.21[-1.18 ; 1.61]$ & $1.59[0.51 ; 2.67]$ \\
Arm muscles & $0.37[0.07 ; 0.67]$ & $-0.02[-0.11 ; 0.06]$ & $0.02[-0.25 ; 0.29]$ & $0.25[0.02 ; 0.47]$ \\
Leg muscles & $1.13[0.33 ; 1.94]$ & $-0.10[-0.37 ; 0.16]$ & $0.20[-0.59 ; 1.00]$ & $0.89[0.27 ; 1.52]$ \\
TG & & & $0.47[-3.84 ; 4.77]$ & $9.94[4.91 ; 14.97]$ \\
Body weight & $6.41[4.12 ; 8.71]$ & $2.86[-0.87 ; 6.59]$ & $0.80[-2.51 ; 4.11]$ & $4.70[-2.49 ; 11.88]$ \\
Fat & $2.40[0.59 ; 4.21]$ & $2.63[-0.73 ; 5.99]$ & $-1.07[-3.75 ; 1.61]$ & $2.28[-3.93 ; 8.49]$ \\
Muscle & $2.30[0.27 ; 4.33]$ & $0.19[-1.47 ; 1.85]$ & $-0.12[-0.78 ; 0.53]$ & $0.24[-0.17 ; 0.65]$ \\
Arm muscles & $0.29[0.16 ; 0.41]$ & $-0.09[-0.34 ; 0.16]$ & $-0.29[-1.06 ; 0.47]$ & $1.63[-1.41 ; 4.67]$ \\
Leg muscles & $1.38[0.26 ; 2.51]$ & $0.12[-1.21 ; 1.45]$ & & \\
LADG & & & $0.17[-1.01 ; 1.34]$ & $6.10[3.83 ; 8.37]$ \\
Body weight & $3.75[2.81 ; 4.70]$ & $1.64[0.18 ; 3.09]$ & $0.30[-0.66 ; 1.26]$ & $5.40[3.56 ; 7.24]$ \\
Fat & $1.87[1.02 ; 2.73]$ & $2.74[1.41 ; 4.08]$ & $-0.17[-0.53 ; 0.19]$ & $0.58[-0.22 ; 1.38]$ \\
Muscle & $1.11[0.60 ; 1.61]$ & $-0.43[-0.82 ;-0.03]$ & $0.06[-0.10 ; 0.22]$ & $0.36[-0.02 ; 0.74]$ \\
Arm muscles & $0.10[-0.24 ; 0.44]$ & $-0.13[-0.47 ; 0.22]$ & $-0.17[-0.52 ; 0.17]$ & $0.18[-0.44 ; 0.81]$ \\
Leg muscles & $0.57[0.13 ; 1.01]$ & $-0.07[-0.24 ; 0.10]$ & &
\end{tabular}

Italicized values are statistically significant $(p<0.05)$, negative values denote increase in the body composition parameters $C I$ confidence interval, $D G$ distal gastrectomy, $T G$ total gastrectomy, $L A D G$ laparoscopy-assisted distal gastrectomy

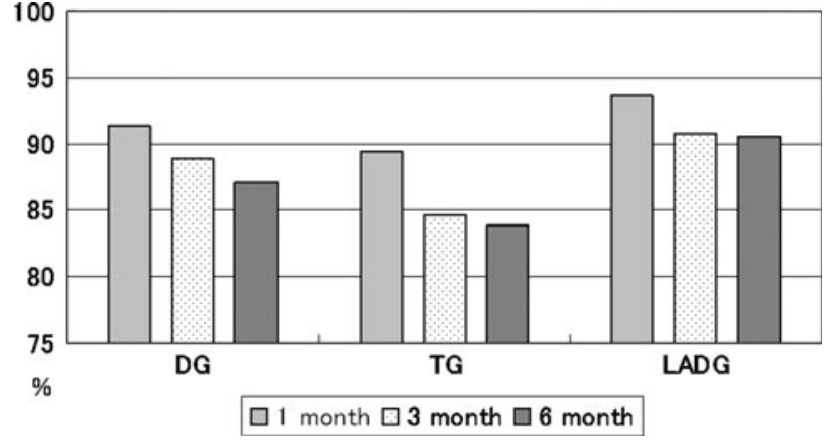

Fig. 1 Body weight expressed as a percentage of the preoperative value at 1,3 , and 6 months after surgery. $D G$ Distal gastrectomy, $T G$ total gastrectomy, $L A D G$ laparoscopy-assisted distal gastrectomy

intake, through loss of appetite. It is not possible at this time to analyze how each of these factors independently affected the outcome.

Low gastric enzyme levels and intestinal bacterial overgrowth are implicated in protein maldigestion [16-18], along with the altered ratio of serum concentrations of essential and branched-chain amino acids reported after gastrectomy which may predispose to muscle atrophy [19]. In addition, muscle mass after surgical intervention could also be affected by the patient's physical activity. The perioperative loss in total muscle mass may have reflected both poor nutritional status and lack of physical activity, and the condition was quite similar for all groups in our

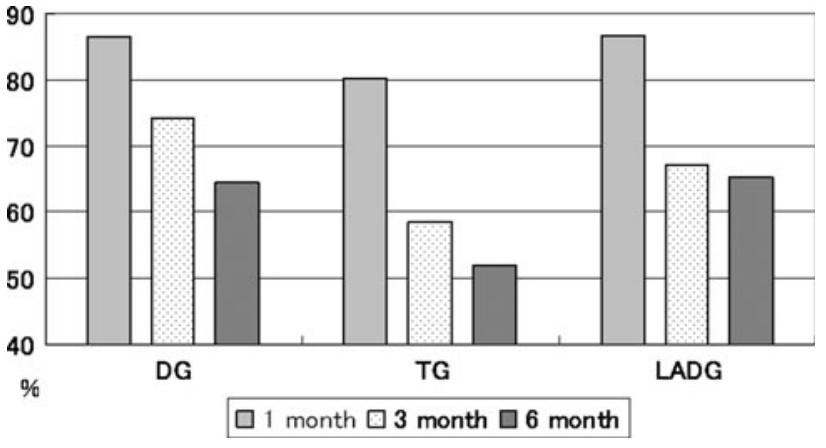

Fig. 2 Total fat mass expressed as a percentage of the preoperative value at 1,3 , and 6 months after surgery. $D G$ Distal gastrectomy, $T G$ total gastrectomy, $L A D G$ laparoscopy-assisted distal gastrectomy

study. The leg muscle mass reduction was also significant in all groups and may have reflected patients' postoperative in-bed immobility. However, both the total muscle mass and leg muscle mass showed remarkable recovery 3 months after the operation in the LADG group. Given that nutritional recovery in terms of fat mass had not been achieved at 6 months postoperatively even for the LADG group, the recovery of the muscle mass may have been due exclusively to near-complete recovery in terms of physical activity.

There is no doubt that factors such as the type of reconstruction, extent of lymph node dissection, and postoperative adjuvant chemotherapy affect outcomes after 


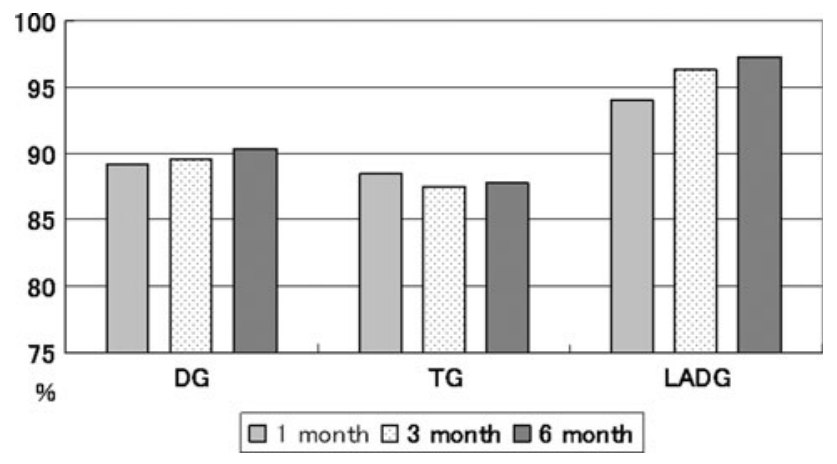

Fig. 3 Total muscle mass expressed as a percentage of the preoperative value at 1,3 , and 6 months after surgery. $D G$ Distal gastrectomy, $T G$ total gastrectomy, $L A D G$ laparoscopy-assisted distal gastrectomy

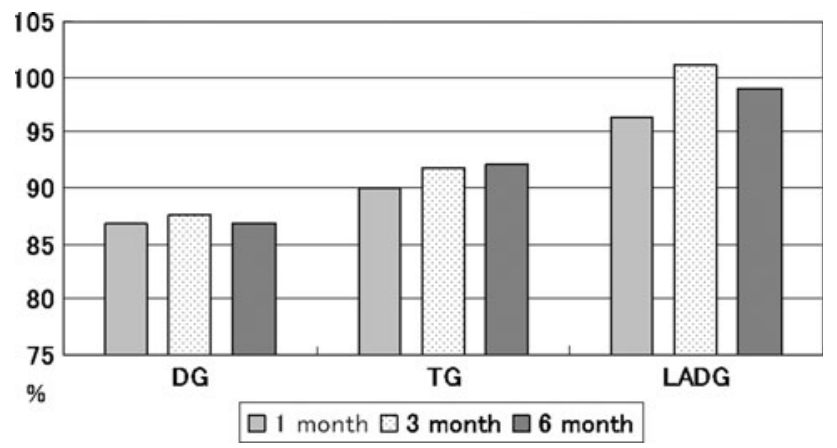

Fig. 4 Arm muscle mass expressed as a percentage of the preoperative value at 1,3 , and 6 months after surgery. $D G$ Distal gastrectomy, $T G$ total gastrectomy, $L A D G$ laparoscopy-assisted distal gastrectomy

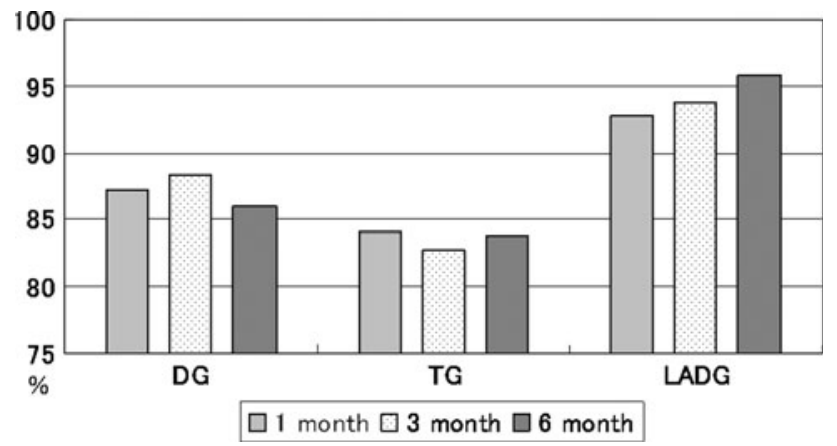

Fig. 5 Leg muscle mass expressed as a percentage of the preoperative value at 1,3 , and 6 months after surgery. $D G$ Distal gastrectomy, $T G$ total gastrectomy, $L A D G$ laparoscopy-assisted distal gastrectomy

surgery. Earlier resumption of food intake with preserved duodenal transit after LADG may have contributed to early nutritional recovery in our patients who had this procedure $[20,21]$. More extended lymph node dissection performed for the DG and TG groups, with greater damage to the celiac nerve plexus, might have affected the postoperative digestive function more seriously. Perioperative chemotherapy, also given almost exclusively to the TG and DG groups, is expected to have had adverse effects on the nutritional status. Thus, the differences observed between the groups in the present study cannot be attributed solely to the operative approach. We were unable to analyze the effect of each of these factors, due to the retrospective and non-randomized nature of the study and the limited number of patients. Evaluation of a greater number of patients with similar backgrounds treated by different approaches is needed to confirm the speculations arising from this study.

In conclusion, after gastrectomy, all patients demonstrated loss of fat and muscle masses during the first postoperative month, regardless of the type of gastric resection or the operative approach. After DG, patients showed a continuous reduction of fat mass during the 6 months of follow-up, whereas recovery was observed 3 months after LADG. In addition, the recovery of muscle mass at 3 months after LADG was remarkable. While more vigorous programs for nutritional support may be warranted after gastric cancer surgery, minimally invasive surgery may facilitate recovery in terms of physical activities.

Acknowledgments The authors thank the attending physicians and the nursing and personal care staff for their contributions. One author (S.A.) was supported by a Novartis Foundation scholarship and by the Epidemiological and Clinical Research Information Network (ECRIN).

Conflict of interest The authors declare that there is no conflict interest.

\section{References}

1. Katsube T, Konnno S, Murayama M, Kuhara K, Sagawa M, Yoshimatsu $\mathrm{K}$, et al. Changes of nutritional status after distal gastrectomy in patients with gastric cancer. Hepatogastroenterology. 2008;55:1864-7.

2. Strong VE, Devaud N, Allen PJ, Gonen M, Brennan MF, Coit D. Laparoscopic versus open subtotal gastrectomy for adenocarcinoma: a case-control study. Ann Surg Oncol. 2009;16:1507-13.

3. Mochiki E, Nakabayashi T, Kamimura H, Haga N, Asao T, Kuwano H. Gastrointestinal recovery and outcome after laparoscopy-assisted versus conventional open distal gastrectomy for early gastric cancer. World J Surg. 2002;26:1145-9.

4. Lee SI, Choi YS, Park DJ, Kim HH, Yang HK, Kim MC. Comparative study of laparoscopy-assisted distal gastrectomy and open distal gastrectomy. J Am Coll Surg. 2006;202:874-80.

5. Lee JH, Yom CK, Han HS. Comparison of long-term outcomes of laparoscopy-assisted and open distal gastrectomy for early gastric cancer. Surg Endosc. 2009;23:1759-63.

6. Hwang SI, Kim HO, Yoo CH, Shin JH, Son BH. Laparoscopicassisted distal gastrectomy versus open distal gastrectomy for advanced gastric cancer. Surg Endosc. 2009;23:1252-8.

7. Kiyama T, Mizutani T, Okuda T, Fujita I, Tokunaga A, Tajiri T, et al. Postoperative changes in body composition after gastrectomy. J Gastrointest Surg. 2005;9:313-9. 
8. Liedman B, Andersson H, Bosaeus I, Hugosson I, Lundell L. Changes in body composition after gastrectomy: results of a controlled, prospective clinical trial. World J Surg. 1997;21:416-20.

9. Fujiwara M, Kodera Y, Kasai Y, Kanyama Y, Hibi K, Ito K, et al. Laparoscopy-assisted distal gastrectomy with systemic lymph node dissection for early gastric carcinoma: a review of 43 cases. J Am Coll Surg. 2003;196:75-81.

10. Fujiwara M, Kodera Y, Miura S, Kanyama Y, Yokoyama H, Ohashi N, et al. Laparoscopy-assisted distal gastrectomy with systemic lymph node dissection: a phase II study following the learning curve. J Surg Oncol. 2005;91:26-32.

11. Furukawa $H$, Imamura $H$, Kodera $Y$. The role of surgery in the current treatment of gastric carcinoma. Gastric Cancer. 2002;5:13-6.

12. Sakuramoto S, Sasako M, Yamaguchi T, Kinoshita T, Fujii M, Nashimoto A, ACTS-GC Group, et al. Adjuvant chemotherapy for gastric cancer with S-1, an oral fluoropyrimidine. N Engl J Med. 2007;357:1810-20.

13. Bae JM, Park JW, Yang HK, Kim JP. Nutritional status of gastric cancer patients after total gastrectomy. World J Surg. 1998;22:254-60.

14. Armbrecht U, Lundell L, Lindstedt G, Stockbruegger RW. Causes of malabsorption after total gastrectomy with Roux-en-Y reconstruction. Acta Chir Scand. 1988;154:37-41.

15. Bradley EL 3rd, Isaacs JT, Mazo JD, Hersh T, Chey WY. Pathophysiology and significance of malabsorption after Roux-en-Y reconstruction. Surgery. 1977;81:684-91.
16. Murawa D, Murawa P, Oszkinis G, Biczysko W. Long-term consequences of total gastrectomy: quality of life, nutritional status, bacterial overgrowth and adaptive changes in esophagojejunostomic mucosa. Tumori. 2006;92:26-33.

17. Brăgelmann R, Armbrecht U, Rosemeyer D, Schneider B, Zilly W, Stockbrügger RW. Nutrient malassimilation following total gastrectomy. Scand J Gastroenterol Suppl. 1996;218:26-33.

18. Iivonen MK, Ahola TO, Matikainen MJ. Bacterial overgrowth, intestinal transit, and nutrition after total gastrectomy. Comparison of a jejunal pouch with Roux-en-Y reconstruction in a prospective random study. Scand J Gastroenterol. 1998;33:63-70.

19. Saito A, Noguchi Y, Yoshikawa T, Doi C, Fukuzawa K, Matsumoto A, et al. Gastrectomized patients are in a state of chronic protein malnutrition: analyses of 23 amino acids. Hepatogastroenterology. 2001;48:585-9.

20. Huscher CG, Mingoli A, Sgarzini G, Sansonetti A, Di Paola M, Recher A, et al. Laparoscopic versus open subtotal gastrectomy for distal gastric cancer: five-year results of a randomized prospective trial. Ann Surg. 2005;241:232-7.

21. Miholic J, Meyer HJ, Müller MJ, Weimann A, Pichlmayr R. Nutritional consequences of total gastrectomy: the relationship between mode of reconstruction, postprandial symptoms, and body composition. Surgery. 1990;108:488-94. 